\title{
THOMAS R. MOORE
}

https://orcid.org/0000-0002-6614-2330

University of Antwerp and Royal Conservatoire of Antwerp (ARIA)

\section{Tools of the Trade: Click-Tracks and Conductors}

\begin{abstract}
This essay will examine the manner in which composers and artistic directors have used conductors and click-tracks within the context of new music ensembles performing integrative concerts. The analyses and examples provided will rely for the most part on material gathered during in-depth interviews that I conducted with artistic directors, composers, conductors, and musicians, all of whom are professionally active in the new music field in Europe (and beyond). I will examine the application of both click-tracks and conductors and demonstrate that their implementation represents an active choice made by either the composer and/or artistic directors. Both click-tracks and conductors are viewed by the interviewees as potential tools with somewhat overlapping possibilities and capacities and their presence is no secondary phenomenon of the music. They become instead a means for the above actors to meet their objectives, be they artistic, pragmatic, technical, or otherwise.
\end{abstract}

KEYWORDS: Conducting, Click-Track, New Music conducting, click-track, new music

\section{Introduction}

As part of my doctoral research at the above-mentioned institutes, I have had the good fortune to meet and interview a diverse array of professionals in the new music field. I talked with thirty composers, conductors, artistic directors, curators, and musicians all throughout Europe in an attempt to gain new and firsthand information on both the artistic and socio-economic motivations for utilizing conductors in new music ensembles. During the interviews, the topic of click-tracks seemed to arise of its own will, despite the lack on my part of any specific questions to that regard. That was striking and took me a little by surprise. I would therefore like to take the time to share their stories and statements about click-tracks and conductors in an attempt to analyse and coalesce the shared experiences.

Many interviewees responded that they would expect a conductor to be responsible for structure and time. Similarly, they also pointed out how a click-track could be deployed for the same goals. Some even suggested that a click-track was an adequate replacement for a conductor. However, as the interviews progressed, 
a more refined trend appeared: artistic directors and composers see both conductors and click-tracks as tools. They can employ these tools, develop, and redefine them to meet their artistic and pragmatic goals. Though there is significant overlap, both a click-track and conductor have their own distinct value and can indeed be utilized simultaneously as well.

In this essay, I will first offer an overview of the discussions I had with the interviewees in regard to technical coordination of pieces, rehearsals, and concerts. Then I will delve into the described visual artistic utility of a click-track, conductor, or both. The interviewees have persuaded me, and I will detail it in this essay, that the application of click-tracks and conductors is an active choice made by composers and artistic directors. Their presence is no secondary phenomenon of the music because of a need for coordination but is a means for the above actors to meet their objectives, be they artistic, pragmatic, technical, or otherwise.

\section{Note}

Throughout this essay I will often refer to 'conductors' and 'new music'. Unless otherwise specified, the conductors and conducting to which I refer in these pages will be those specialized in working with contemporary music ensembles, all of whom (both ensembles and conductors) have arisen out of the Western art music tradition and perform integrative concerts. ${ }^{1}$ New music refers to music written since 1950 and also in the Western art music tradition. Mostly this term will apply to ensemble music, however I will attempt to be vigilant while applying this term and make it clear when it means something other than this characterization.

\section{Technical artistic coordination}

'A conductor plays time', said Filip Rathé, founder and for the last 20 years, the artistic director and conductor of the Belgium-based Spectra Ensemble. 'Musicians play sound and I play time'. We were discussing how he sees his role as conductor and the manner in which he interacts with the musicians of Spectra. In his view, the musicians are responsible for the sounds they produce and Rathé helps them to make those sounds in time. In the narrow sense, time can mean the physical synchronization of the musicians, or more broadly, the global presentation of a piece or program, as well as the structuring of a rehearsal process. All can be organized using time as a tool, a tool that Rathé and other conductors use as their instrument.

\footnotetext{
${ }^{1}$ Integrative concerts, meaning video, light and sound design (e.g. live electronics), decor, and utilization of a conductor are all integral parts of the concert programming. See e.g. video Introduction of Nadar Ensemble: https://www.youtube.com/watch?v=hpKlfG7dVXM; and the documentary Staging of Delusion of the Fury, Harry Partch Project, MusikFABRIK: https://www.youtube.com/watch?v=TKUoKBivZ7c; Matthynssens (2020).
} 
I would first like to examine the narrow sense. Conventionally speaking, conductors display time using gestures that are trained and recognizable to (classically) trained musicians. If a piece is written in a 4/4 time signature (and divided in 4 equal parts) then there are specific gestures that follow a set pattern that indicate each of the 4 beats. In this manner, a conductor communicates the tempo to the musicians and temporally synchronizes the written score for the entire ensemble. The time it takes for the conductor to travel between two beats becomes the collectively accepted tempo. For example, if the conductor beats the ' 1 ' and then beats the ' 2 ' 1 second later, the tempo would then be 60 beats per minute. The conductor, beating the pattern, physically and literally shows a pulse that demonstrates time.

Click-tracks and video scores (i.e. musicians' parts in which a cursor runs along the page indicating when specific passages should be played) do the same thing. They sonify or visualize the tempo. Click-tracks are often used in contemporary music to synchronize an ensemble with fixed media (films, tapes,

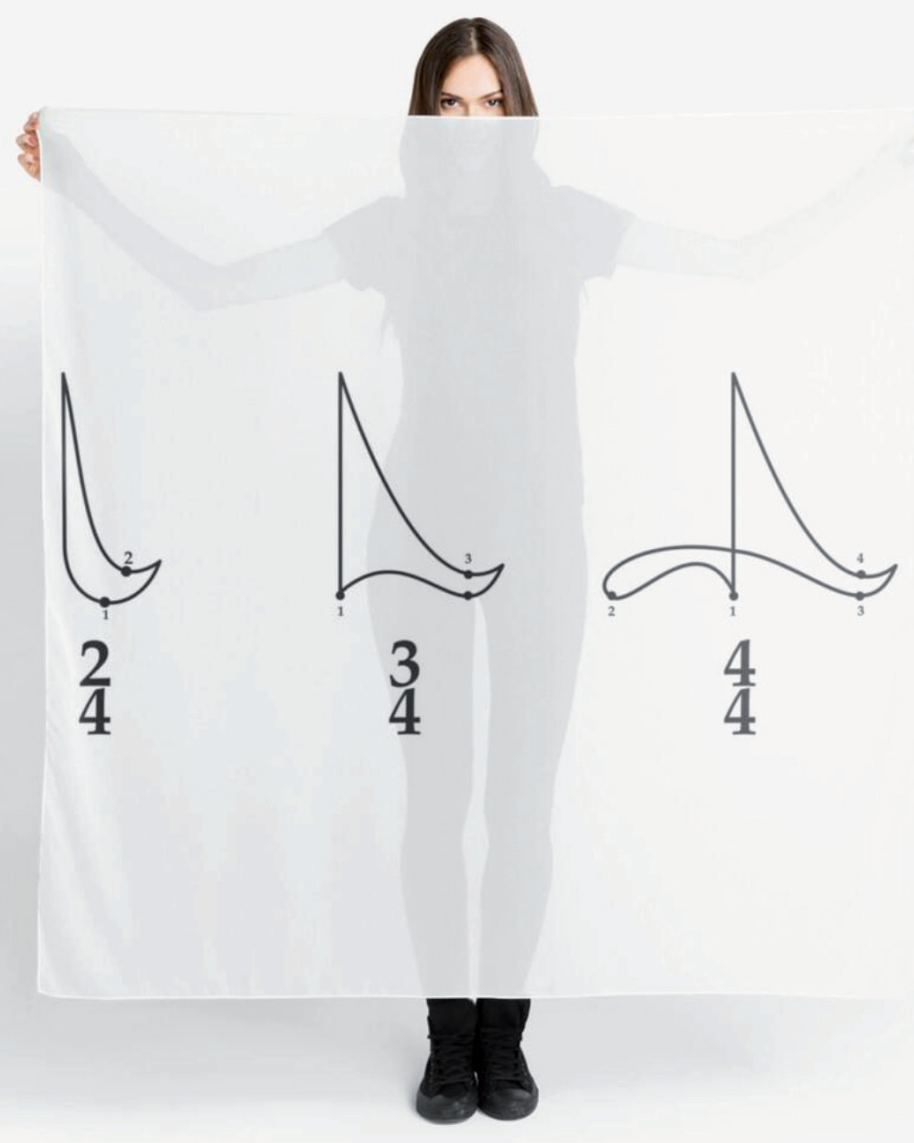

Figure 1. Common conducting patterns, (c) Redbubble 
electronics, etc.) or the musicians themselves if the music is extremely complex, rehearsal time is short, or the musicians simply cannot see one another. Composer and artistic co-director of Nadar Ensemble Stefan Prins told me about his first time using a click-track in a composition to synchronize the musicians:

\begin{abstract}
I composed Fremdköper 2 (2010) for Nikel Ensemble and it would be premiered at Darmstadt [Int. Ferienkürse für Neue Musik in the same year]. I don't remember if it was Tom De Cock or Yaron Deutsch who asked me, but the ensemble requested that I make a click-track for rehearsals to make things more efficient. I actually hadn't thought about that before. I thought they would just be able to perform it as chamber music; perhaps deciding who would conduct when it was necessary, but just as a chamber music ensemble. We used a click-track in the first rehearsals and it was really an eye-opener for me. It was so easy and useful for them in rehearsals to just put the click-track on the speakers and simply go to a specific measure, lower the tempo, etc. This definitely opened up, for me, the possibilities to work with click-track and it being a tool to be considered. And of course it helped that they were not like 'aargh! Click-track - I don't wanna play with click-track!' They were totally open for it and even encouraged it.
\end{abstract}

Christof Löser, conductor and head of the new music studio at the Hochschule für Musik und Darstellende Kunst Stuttgart, described during our interview how he teaches and prepares composition students for performance situations. He admits that students often do not think of performance and rehearsal coordination before they hand their scores to the musicians:

I always try to discuss with my students in seminars and in my conducting class with the composers how music could and can be coordinated. Should it be coordinated? Which concepts already exist? What about coordination of groups? Sometimes their works are only for four people and the composer thinks, 'No, no, I don't want a conductor.' But then we get into the first rehearsals and he or she realizes it's not so easy. So they take a click-track. Or they ask somebody to conduct. So the conductor is used or the click-track is used. However, I say this to demonstrate that I try to instill in them that in new music you have to find new ways of coordination. I try to show them music that already exists and work with some specific coordination techniques so that if they do use a conductor, it is a conscious choice and not a last resort.

Here Löser demonstrates that both a conductor and click-track can be deployed by composers to meet the need of temporal synchronization. He seems to present it as a choice of one or the other: either a conductor will be used or a click-track - not both. Prins makes a similar argument in regard to his choice for a click-track in Generation Kill (2012), a work for 4 musicians, 4 game-controllers, video, and electronics:

There was an option to use click-track. This is something that we at Nadar are comfortable with. It's not a taboo. That also helped me make the choice of not using a conductor and instead using a click-track. It just makes much more sense in the piece. Generation Kill and Mirror Box Extensions (2015), too, create this feeling of a piece being a machine that works by itself somehow. Whether it's controlled behind the scenes via a click-track or not, is less important, because it's behind the scenes, it's invisible, which cannot be said of a person standing in front conducting.

There are, however, situations in which both a conductor and a click-track are used for the sake of technical coordination. At the premiere of composer 
Michael Beil's exit to enter by Nadar in 2012 at the Acht Brücken Festival in Cologne, Germany, Beil insisted on making the click-track audible only to the conductor and light operator. When I asked him about this specific case, he said:

I did that because I thought it would be a relief for the musicians not to have to be on a clicktrack. I still think that. However in special contexts, the click-track can be a replacement of the conductor, such as in pieces that run with a fixed tape or a fixed command line, like my pieces.

Beil employed a conductor and a click-track to temporally synchronize the musicians with his fixed media (video and electronics). His experience with musicians up until that point was similar to the anxiousness Prins described above. Musicians do not like to play with click-tracks because they feel that it hinders their ability to play together with their fellow musicians. However, after some encouragement from the ensemble's artistic direction, Beil had a change of heart, removed the conductor, and since the reprise of the piece, it has only been performed with a click-track (and no conductor).

Georges-Elie Octors, the recently retired conductor of ICTUS, described a similar situation to the premiere of exit to enter, namely Fausto Romitelli's video opera Index of Metals (1975). In this piece, he alone had click-track in his in-ear monitors and grew to know the piece so well that he was able to create both a live feeling and remain synchronized with the fixed media:

Conducting with a click-track in your ears, it is possible of course - and I have done it very often. Somehow you are not in the music anymore because you have to keep this click in your mind. However, for some music, for example Romitelli, if you really know the music quite well, then you can play with the click-track; be a kind of rubato.

Octors and ICTUS weighed two technical necessities. On one side of the scale they needed to be synchronized with Romitelli's fixed media. And on the other side they had to play together as an ensemble while being able to make spontaneous live artistic choices. They concluded that the best manner in which to achieve a good balance was to utilize both a click-track and a conductor. Octors, by knowing the piece, click-track, and ensemble so well, had the ability to grant artistic freedom and still keep the collected musicians within an acceptable margin of synchronization. This represents an example of an active choice made by both the artistic direction of the ensemble to utilize a conductor and a click-track simultaneously for two technical artistic goals.

Christof Löser provided another example. We were discussing the influence conductors can have on the audience's perception of a piece and he coined the term, 'tempo in space.' The tempo to which he refers is an impression of time that is collectively palpable to an audience during a performance. The particular pieces to which he applied this term were spatialized compositions by Michael Maierhof. Often in these pieces, the conductor was purposely hidden from the audience, staged behind them. So the tempo they feel in space is not one that is perceived visually or granted by the conductor's gestures. It is instead a discernable feeling of collective tension that the performers create. The audience thus vicariously feels the conductor's 'tempo in space' through the performers' collectively created and synchronized tension (Moore, 2019). 
Here is Löser describing his concerns with video scores and click-tracks as replacements for conductors:

The video score is a completely different and new possibility. I think it helps the musicians make the sounds and rhythms better because it is clear when they should be played. But you lose their tempo in this space. There is no feeling of tempo in space. Also, I witnessed some Maierhof performances with click-tracks and I'm quite certain that this is not what he originally intended. It's just easier for ensembles without a conductor - and just to invite a conductor only to conduct a quartet, who does that? However, without the conductor, ensembles risk falling back into click-track islands with very little palpable internal communication.

Maierhof's newest works are often performed with a click-track. However, to achieve and coordinate discernable shifts in the 'tempo in space', Löser asserted that both a click-track and a conductor must be deployed.

Pieter Matthynssens and I talked about one such Maierhof work, EXIT $F$ (2011) for Ensemble and four hot air balloons, in which he, as artistic co-director of Nadar ensemble, was playing with the idea of re-inserting a conductor in the performance of this piece specifically for the audience's benefit. In this particular part of our conversation, we talked about deploying a conductor to frame the piece and the silences within Maierhof's work:

It's interesting to me that we now consider bringing back a conductor after having removed him or her from the line-up. Originally we did do it with a conductor because all the musicians were together on one stage. This was great for music making. However now I really like the spatialized setup [with the musicians spread out on 8 stages surrounding the public] and probably wouldn't accept it if we had to do it on one stage again. That said, I found it really interesting to see how the silences were perceived in Zonen 6 (2018, Michael Maierhof) when you conducted it. So now we've started to think about re-integrating the conductor [in EXIT F] but just to give the silences. [laughs] A conductor not to get the musicians together, but just to hold the tension of the silence, to show the audience that the piece continues, and to show the ending. With a conductor you feel when a piece has begun and when it has ended. They clearly provide a frame.

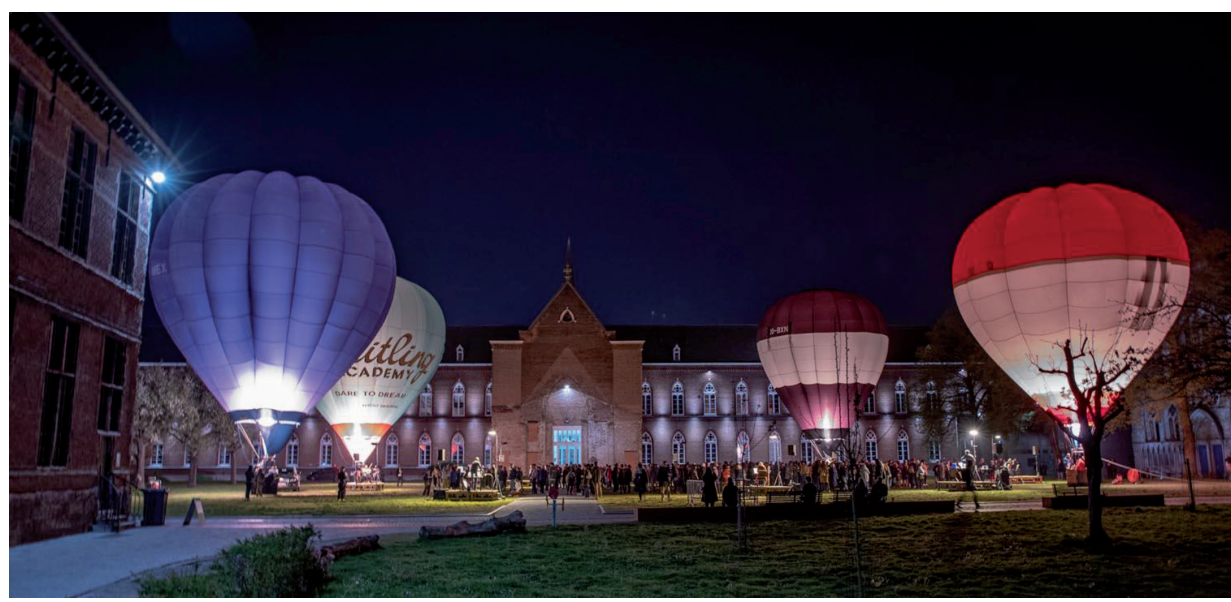

Figure 2. Nadar ensemble performing EXIT F by Maierhof, (C) Kobe Wens 
Arguably, a technical duty of the conductor is to show, keep, shift, and determine time for the musicians with which he or she performs. Above it has been demonstrated that a click-track or video score can also perform this duty in a satisfactory or sometimes preferable manner. In the three pieces Prins described, both technically and artistically it was a superior solution for musicians and composer. Also for Beil's exit to enter, the use of click-track as a complete replacement of the conductor proved the better option. However, as the interviews showed, a conductor and a click-track are tools with overlapping technical capacities that can alco be deployed simultaneously to achieve new results such as described by Octors and exemplified by Maierhof, Löser, and Matthynssens. In the case of Index of Metals, the conductor served as a bridge between the live performance and the fixed media. In the Maierhof's music, a 'tempo in space' is only palpable to an audience when all performers are collectively synchronized not just in time but also in tension. A click-track can be used to temporally synchronize an ensemble while a conductor's physical gestures maintain and unify the required tension.

\section{Visual artistic utility}

The active choice that ensembles, their artistic directors, and composers make in regard to utilizing a conductor, click-track, or both is not only based upon the necessities of coordination and/or synchronization. The visual impact of a conductor's presence and its perceived effect on the audience is also taken into consideration. Conductors are staged performers that make gestures, often in the vicinity of an audience, to practice their art. The conductor's physicality (presence and gestures) creates, meets, and/or upsets expectations. Moreover, the presence of a conductor can give an impression of hierarchy on stage, as Stefan Prins explained as part of his decision not to utilize a conductor in Generation Kill:

In Generation Kill, a conductor would have obfuscated this image entirely by bringing in references that had nothing to do with the piece itself, references to orchestral music making, to the 'maestro' whose emotions are beamed to the ensemble or orchestra who are his (the stereotypical maestro is unfortunately still expected to be male) minions - so references to hierarchy and traditional music making. Generation Kill, conceptually, is much closer to the world of gaming than to the world of orchestral or ensemble music making. In gaming there is not such a hierarchy, it functions more in a rhizomatic network structure, rather than a pyramidal structure. And aesthetically the piece refers more to the world of noise music than conducted ensemble music. Within the piece, the only lines of communications that I wanted to be present were between the game controller performers, their avatars, and the instrumentalists. Adding a conductor would add another line of communication that would entirely obfuscate the conceptual dimensions.

There is another thing that personally disturbs me often in conducted music, not so much conducted romantic orchestral music, but more contemporary conducted ensemble music. A conductor for me often spoils the surprise because his or her gestures alert you to what's coming next, they are 'telegraphing' a big rupture or a climax. Of course, this also depends very much on the conductor's character. I find it quite disturbing when the conductor has such a big ego that it's more about his or her riding the bull than the bull itself, metaphorically speaking. 
Simon Steen-Andersen sought and applied these 'references to orchestral music making' in his piece Black Box Music (2012) for performer, amplified box, spatialized sinfonietta, and video. As Steen-Andersen described it, the performer, a conductor-like figure was deployed as the 'image of the conductor' to play on the audience's expectations. During our interview, I asked him how he came to make this choice and how both the role of the conductor and the expectations thereof play a key role in Black Box Music:

\footnotetext{
The conductor's function is to lead the ensemble during rehearsals, maybe also verbally, and at the concert, just by using gestures. The moment, of course, that we have a click-track, we can also easily do the piece without a conductor. So that is what I mean by taking away the function of the conductor. The conductor is, in a way, an official component of a concert. I used that image as a starting point as well as the expectations that we have from this very common situation that everybody knows: the conductor in front of the orchestra. Now that being said, I did not originally intend for the piece to have a click-track. Actually the intention was to keep the functionality while deconstructing it. Unfortunately that didn’t really work.

[...]

What I realized, however, is that even though I thought that it would destroy the whole piece if I gave in and did it with a click-track, it did not make any real difference in a negative way for the audience. If the audience can directly see that the piece is playing with the system and sometimes deconstructing that system, that turns out to be enough. They've got the image and the same expectations. The deconstructions work when it gets off and [the audience] still has this feeling that there is a dissonance when [the ensemble] goes into another tempo. They also still have the feeling of arriving back home to consonance, to tonic when it finally clicks and the musicians and conductor are on the same beat, together again.
}

The 'dissonance' and 'consonance' to which Steen-Andersen refers is visual and audible as well as harmonic and rhythmical. He builds on the audience's expectation that the conductor's gestures will somehow be in-synch with the sounds and rhythms of the musicians, thus creating a consonance of expectations and results (or at least a discernable pattern will appear). When SteenAndersen commences to 'deconstruct' his piece, meaning the ensemble plays in a different tempo than the conducting pattern would imply, than the audience's expectations no longer match the results, creating dissonance. In the final version of the piece, he actively chose to use a click-track for temporal synchronization, while for visual and compositional considerations, the active choice to utilize a conductor of course remained.

Another example of a piece in which a conductor and click-track were used simultaneously, and in which the conductor was deployed for visual artistic considerations, is Alexander Khubeev's Ghost of Dystopia (2014, rev. 2019) for ensemble and augmented conductor. In addition to the click-track, Khubeev wrote a video score for the conductor because it is impossible (for the conductor) to turn pages or use a foot switch during concerts. Khubeev created an instrument in which the conductor is literally bound hand and foot. Each finger as well as the elbows, knees, and ankles are bound by string to plastic boxes and each box scrapes along glass plates, creating a rich multiphonic soundscape (Khubeev, 2019). The role of the conductor, in this piece, takes on the mantle of an instrumental conductor.

In an earlier essay, I argued that Khubeev, in Ghost of Dytopia, has instrumentalized the role of the conductor for two reasons (Moore, 2020). First, to 
'question the role of the conductor' and, secondly, 'to tell a story'. He questioned the role by choreographing every movement of the conductor, thus leaving no room for spontaneous gestures or conventional duties such as assisting the musicians with entrances, balance, and synchronization. He thereby composed both functional and non-functional conducting gestures creating a visually dissonant situation for the audience that is similar to Steen-Andersen's Black Box Music. The story itself also questions the role and conventional hierarchy of a conducted new music ensemble. According to Khubeev, the story of Ghost of Dystopia is told in three parts, each corresponding to a section in the musical score. It begins with the ensemble and conductor on equal footing, all bound to their instruments and producing similar soft multiphonics. This represents a society of a bound but equal citizenry. In the second section, the conductor breaks free of a portion of the instrument, rises up, and begins to experiment with conducting patterns. The conductor ascends above his or her fellows and begins to lead and direct. In the final section, the conductor breaks completely free of the composer's instrument and brutally and increasingly efficiently conducts his or her fellow musicians. The audience is now witness to a dictator. The piece and story end with a merciless gong and chain crash. The conductor stands in a Christ-like pose, begging the question, is he or she dead or become a god?'2 For practical reasons, Khubeev needed a click-track and video score to synchronize the ensemble. However, to tell his story, he required a conductor.

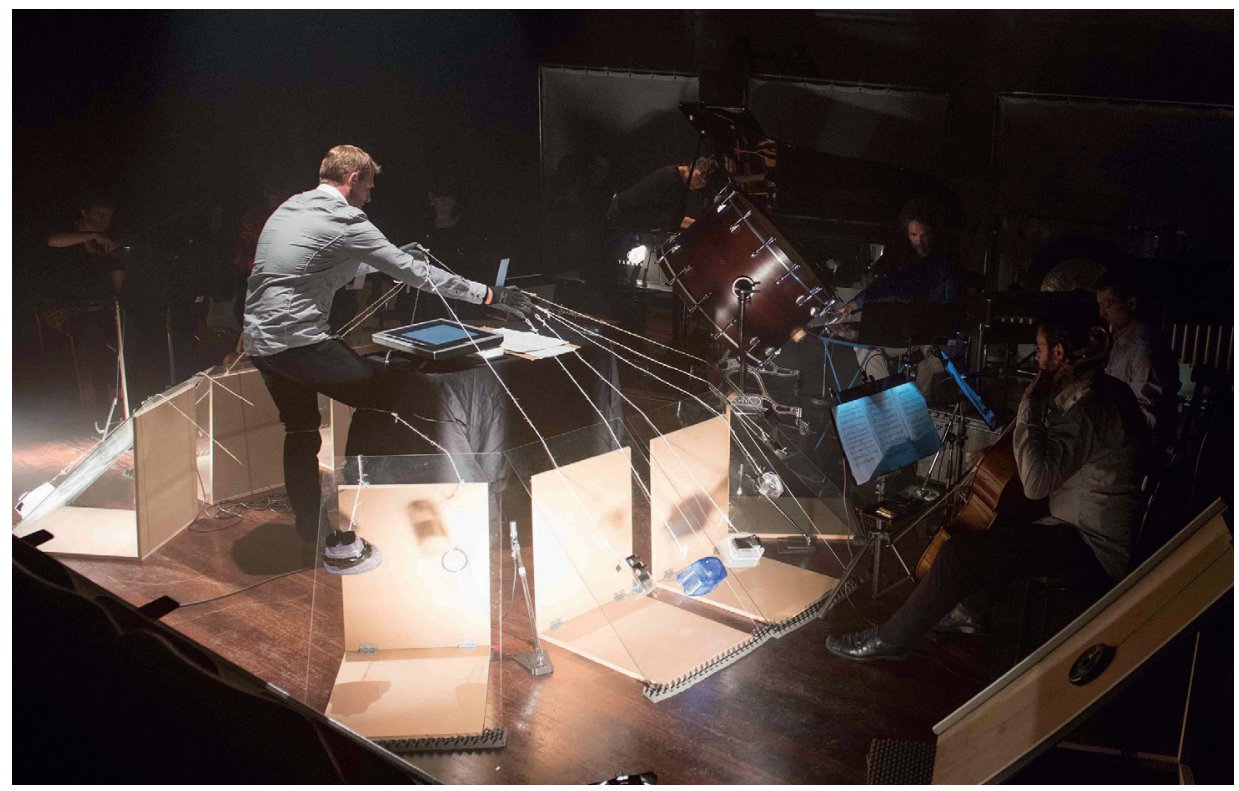

Figure 3. Nadar Ensemble performing Ghost of Dystopia by Khubeev, (C) Anna van Kooij

${ }^{2}$ All quotes in this paragraph come from a conversation with Alexander Khubeev with the author (2019). 
Stefan Prins, during our conversation displayed an obvious reluctance to implementing a conductor in specific pieces. Yet, he also demonstrated an insightful awareness to their potential. I therefore asked him about one piece in particular in which the conductor was deployed in both a conventional manner to lead the musicians, as well as played an exceptional role in the choreography and staging. The work, titled Third Space (2018), is an integrative piece for dancers, musicians, video, and electronics and was written in collaboration with choreographer Daniel Linehan:

We, Daniel and I, first asked ourselves, 'what can a conductor give us?' The physicality of this conducting became something really important to that piece. Daniel and I chose him [Bas Wiegers, in our case] to be the only person - the only physically present person in the first part [of the piece]. We had him facing the audience so that we could literally draw attention to his gestures. So, instead of hiding them, we wanted to spotlight them. His movements then served as bridging material with what the dancers would do throughout the piece. The physicality of his gestures became part of the choreographed material. We weaponized his gestures.

The other reason why we have the conductor out front at the beginning and turned him around to face the audience was because we wanted to create this feeling of intimacy. Normally the audience cannot see his face. It's the privacy and the privilege of the orchestra. By turning that around he suddenly becomes very vulnerable. This vulnerability gave us a way to create a feeling of intimacy. It made it possible early on in the piece (and the process, too) to ask the questions, 'What is privacy?' And, 'What is intimacy?' So later when the audience itself moves onto the stage, it becomes a logical consequence of the beginning. So in that sense, we instrumentalized the conductor, too.

Prins and Linehan used a click-track and video score to synchronize the musicians with the fixed media. This gave them the freedom to then take advantage of the full potential that the conductor's presence has to offer. They actively chose to instrumentalize the conductor's role and Wiegers himself. His gestures were not choreographed - he was allowed and even encouraged to conduct in a functional manner. However, Prins and Linehan gave his gestures a redefined function as they became part of the dancers' choreography and role. During parts of the piece, the dancers' gestures so resemble Wiegers' conducting that one may begin to question who is actually doing the physical conducting. The dancers' proximity to the musicians (they are staged very close to each other) also encourages greater than normal interaction between the three roles: conductor, dancer, and musicians. As the piece draws to a close, Wiegers takes on a less functional role (towards the musicians) and becomes one of the dancers himself, moving off stage and being visible to the audience only through a live camera feed. There is a clear and developed arc in the conductor's role in Third Space, and while Wiegers was deployed in a traditional sense to conduct musicians, too, his role was also clearly 'weaponized' and instrumentalized to reach Prins' and Linehan's visual artistic goals. ${ }^{3}$

${ }^{3}$ Third Space (Prins/Linehan) - KAIROS - trailer: https://youtu.be/UwPiSjc2pIY; Moore (2019). 


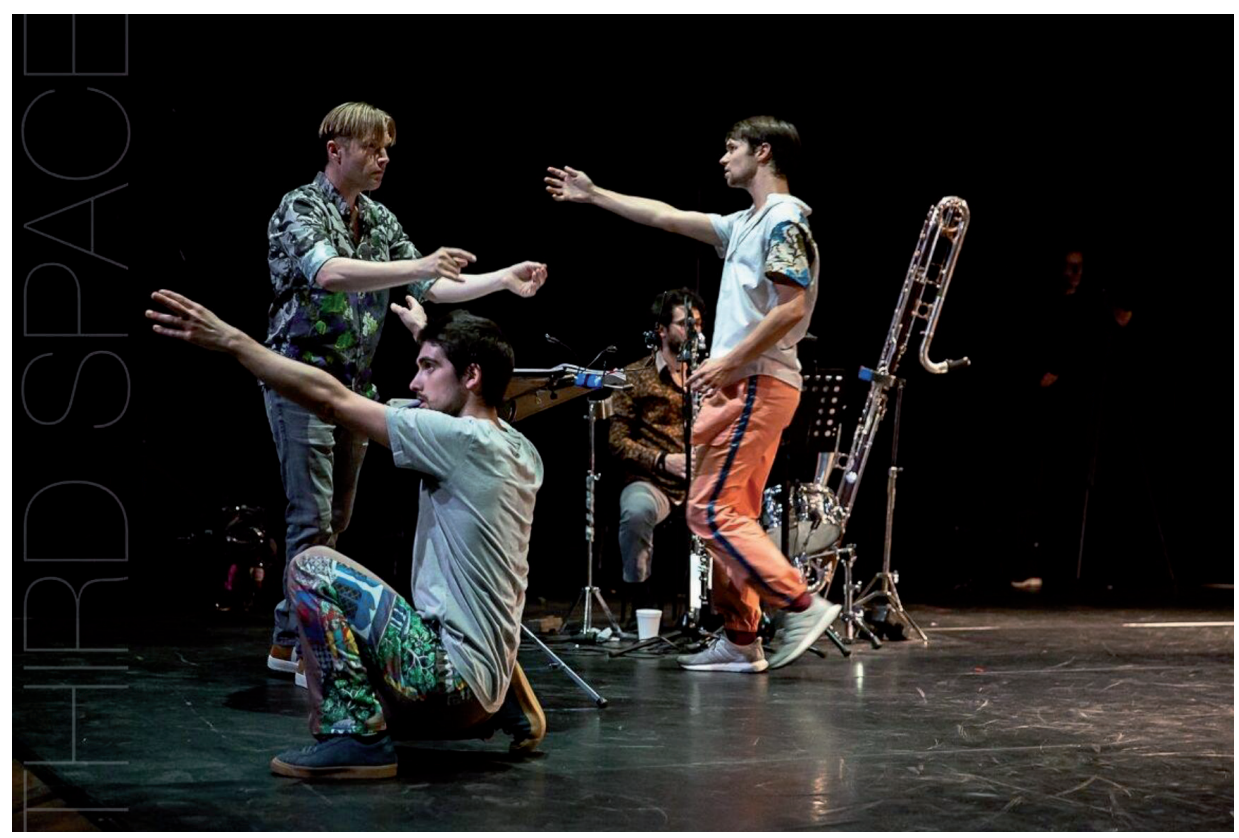

Figure 4. Bas Wiegers and Klangforum Wien performing Third Space by Prins and Linehan,

(C) Gaëlle Marras

The physical presence of the conductor can influence the audience's perception of a piece and/or program. Stefan Prins and Alexander Khubeev both detailed the expectation that simply having a conductor on stage will lead to an assumption of a hierarchy. For Prins, this was a reason not to use a conductor in Generation Kill. Khubeev, however, relied on these perceptions to tell the story of the rise and possible fall of a dictator. Prins also talked of conductor's gestures 'giving things away,' meaning audiences will grasp a pattern and expect consistency between visual gesture and audible sound. Simon Steen-Andersen agreed with that observation and made it a part of the compositional structure of Black Box Music. In Third Space, Prins and Linehan developed and redefined the role the conductor to generate new perspectives and create a level of intimacy. In the four pieces discussed in this section, the interviewees/composers all chose to use click-tracks for the technical artistic synchronization and coordination of the ensemble. They also all weighed the visual impact of a conductor on the audience leading to an active choice of whether or not to simultaneously deploy a conductor.

\section{Conclusion}

In integrated concerts, artistic and programming choices are made that go beyond the purely musical. Artistic directors and composers consider lights, sound design, staging, video, costumes, and even the presence of a con- 
ductor when making such decisions. For the sake of synchronization and coordination, the use of a click-track or video score is often considered. However, even though coordination is also conventionally expected of the conductor, the interviews lead me to conclude that this does not necessarily prompt a choice between the utilization of one or the other. Both are seen as potential tools with somewhat overlapping possibilities and capacities. In the examples cited above, the two were utilized simultaneously for both the purpose of synchronization as well as for the benefits ascribed to the conductor's physical presence. Their usage was no secondary phenomenon of the music, but rather represents an active choice of the artistic director and/or composer.

\section{References}

Beil, M. (10 October 2019). Interview.

Khubeev, A. (27 March 2019). Interview.

Löser, C. (15 January 2020). Interview.

Maierhof, M. (17 January 2020). Interview.

Matthynssens, P. (21 January 2020). Interview.

Moore, T. R. (2019). Conducting Silence: The use of conducted and measured silences in Michael Maierhof's Zonen 6 for guitar orchestra (2007-2008, 2018). FORUM+ Online. http://www. forum-online.be/nummers/herfst-2019/conducting-silence.

Moore, T. R. (2021). Instrumentalized Conductor, Tempo, 297 (forthcoming).

https://www.dropbox.com/s/k6qq8nryhg59aja/Instrumentalized\%2oConductor.docx?dl=o.

Octors, G.-E. (15 October 2019). Interview.

Prins, S. (23 August and 10 November 2019). Interview.

Rathé, F. (21 January 2020). Interview.

Steen-Andersen, S. (10 November 2019). Interview. 